ESTUDIOS 



\section{1. \\ Derecho civil}



Revista de Derecho

de la Pontificia Universidad Católica de Valparaíso

XXXVI (Valparaíso, Chile, 2011, $1^{\text {er }}$ Semestre)

[pp. 37 - 67]

\title{
La Reserva de Chile a la “Convención de VIENA" DE 1980
}

["The Chilean Reservation to the 1980 Vienna Convention"]

\author{
Francisco José Grob Duhalde* \\ Universidad de Chile
}

\begin{abstract}
Resumen
El trabajo tiene por objeto analizar la reserva de los principios del consensualismo y libertad de forma consagrados en la "Convención de Viena" de 1980, formulada por Chile conforme a los artículos 12 y 96 de la misma Convención. Su propósito es precisar el correcto sentido y alcance que debe atribuirse a esta reserva y, de paso, hacer algunas críticas respecto la forma como ha sido interpretada por la doctrina y jurisprudencia nacionales.

\section{Palabras Clave}

"Convención de Viena" - Compraventa internacional de mercaderías - Reserva chilena de la "Convención de Viena".
\end{abstract}

\begin{abstract}
This article addresses the analysis of the exception of the consensualism and freedom of form principles established in the "Vienna Convention" of 1980, drawn up by Chile according to articles 12 and 96 of the same Convention. Its purpose is to specify the correct sense and scope ascribable to this exception and, also, to make some criticism about the way this has been interpreted by the Chilean doctrine and jurisprudence.

\section{KEYWORDS}

"Vienna Convention" - International Purchase and Sale of Goods - Chilean Exception of the "Vienna Convention".
\end{abstract}

[Recibido el 10 de noviembre de 2010 y aprobado el 28 de abril de 2011].

* Abogado. Licenciado en Ciencias Jurídicas y Sociales de la Universidad de Chile. Diplomado en Derecho Internacional por Washington College of Law de la American University. Ayudante del Departamento de Derecho Económico de la Facultad de Derecho de la Universidad de Chile. Correo: franciscogrob@gmail.com 


\section{INTRODUCCIÓN}

A pesar de su éxito a nivel internacional, contando hoy en día con más de 75 Estados signatarios ${ }^{1}$, para nadie es un misterio que la Convención sobre la compraventa internacional de mercaderias aprobada en Viena en 1980 (en adelante la "Convención de Viena" = CV. o la Convención) ha tenido escasa aplicación práctica en nuestro país. De hecho, a partir de una revisión efectuada a la jurisprudencia nacional sólo es posible encontrar unas cuantas sentencias en las cuales ésta ha sido aplicada. Atribuimos este fracaso, fundamentalmente, al desconocimiento de parte de la doctrina nacional respecto a la correcta aplicación de este cuerpo normativo. En particular, creemos que la reserva del artículo 96 en relación al artículo 12, formulada por nuestro país al ratificar la Convención, ha introducido un elemento de incertidumbre que ha evitado que abogados y jueces la apliquen a los contratos de compraventa internacional, a los cuales está llamada a regular. Es por esto que en el presente trabajo nos abocaremos a clarificar los efectos de la citada reserva, partiendo por un análisis del principio del consensualismo y la libertad de forma en la Convención, para luego analizar las diversas interpretaciones que ha originado su aplicación.

\section{LA “Convención de VienA” en Chile}

El 11 de abril de 1980, tras una conferencia diplomática celebrada en la ciudad de Viena, Austria, 62 Estados provenientes de las más variadas tradiciones jurídicas aprobaron por unanimidad el texto de la Convención.

Pese a haber suscrito el Acta final del tratado como signatario original, nuestro país no ratificó la Convención sino hasta diez años más tarde, esto es, el 7 de febrero de 1990 cuando finalmente efectuó el depósito del instrumento de ratificación ante el Secretario General de la Organización de las Naciones Unidas. En el plano interno, la Convención fue promulgada en virtud del decreto No 544, publicado en el Diario Oficial el 3 de octubre de 1990. Desde esa fecha, la Convención constituye en Chile ley especial para los contratos internacionales de compraventa de mercaderías ${ }^{2}$.

${ }^{1}$ Al 28 de marzo de 2011, 76 Estados habían suscrito la Convención. Para consultar el estado actual de ratificación de la Convención: http://www.uncitral.org/uncitral/ es/uncitral_texts/sale_goods/1980CISG.html

${ }^{2}$ Mereminskaya, Elina. Contratos internacionales e "internacionalización" de contratos nacionales, en Anales de la Facultad de Derecho, 5a época, 1 (Universidad de Chile, 2005). 


\section{EL PRINCIPIO DEL CONSENSUALISMO Y LA LIBERTAD DE FORMA En la “Convención de Viena”}

De acuerdo al artículo 11 CV.: "[...] el contrato de compraventa no tendrá que celebrarse ni probarse por escrito ni estará sujeto a ningún otro requisito de forma. Podrá probarse por cualquier medio, incluso por testigos." Esta disposición lleva envuelta dos ideas fundamentales. Por una parte, consagra el principio del consensualismo en la Convención y, por otra, garantiza el reconocimiento de este principio en materia probatoria estableciendo la libertad de forma a efectos de acreditar el contrato de compraventa internacional ${ }^{3}$.

En armonía con esta disposición, el artículo $29 \mathrm{CV}$. agrega que "[...] el contrato podrá modificarse o extinguirse por mero acuerdo entre las partes". Sin embargo, esto último no será posible si los contratantes, habiendo otorgado el contrato por escrito, acuerdan que toda modificación o extinción por mutuo acuerdo se haga del mismo modo. Dicho de otro modo, prima la autonomía de la voluntad de las partes ${ }^{4}$. Sin perjuicio de esto, la misma disposición agrega que incluso en estos casos "cualquiera de las partes quedará vinculada por sus propios actos y no podrá alegar esa estipulación en la medida en que la otra parte se haya basado en tales actos."

Es importante señalar que el reconocimiento al principio del consensualismo y la libertad de forma no fue, sin embargo, una cuestión pacífica durante los Travaux préparatoires de la Convención ${ }^{5}$. En efecto, al momento de discutirse esta disposición en la Comisión de las Naciones Unidas para el Derecho mercantil internacional (CNUDMI), diferentes Estados manifestaron sus dudas respecto al alcance de esta norma. Algunos temían que el artículo $11 \mathrm{CV}$. anulara las regulaciones nacionales relativas al control de importaciones y exportaciones y que exigen la presentación de ciertos documentos a la autoridad ${ }^{6}$.

La verdad, no obstante, es que esta inquietud puede ser fácilmente solucionada si analizamos el artículo $4 \mathrm{CV}$. De acuerdo a esta disposición, la Convención "[...] regula exclusivamente la formación del contrato de compra-

${ }^{3}$ Rajski, Jerzi, Comments on Article 12, Comments on Article 11, en Bianca, C. - Bonell, M. Commentary on the International Sales Law (Milano, Giuffrè, 1987). En el mismo sentido: Wang, Xiaolin - Andersen, Camila, The Chinese "Declaration against Oral Contracts under the CISG', en Vindobona Journal of International Commercial Law \& Arbitration, 8 (2004), pp. 145-164.

${ }^{4}$ Un caso interesante donde un Tribunal falló en este sentido lo encontramos en el ICC Arbitration Case $\mathrm{N}^{\circ}$ 9117, de Marzo de 1998.

${ }^{5}$ HonNold, John, Uniform Law for International Sales under the 1980 United Nations Convention ( $3^{a}$ edición, La Haya, Kluwer Law International, 1999), sección $127^{\mathrm{a}}$.

${ }^{6}$ En Chile, véase por ejemplo el Documento Único de Salida (DUS). 
venta y los derechos y obligaciones del vendedor y del comprador dimanantes de ese contrato." Por tanto, dado el ámbito de aplicación de la Convención, ésta no puede interferir con las regulaciones nacionales antes mencionadas. Por lo demás, durante los travaux préparatoires se dejó en claro que "todas las sanciones administrativas o penales por infracción de las normas de cualquier Estado que requieran que dichos contratos sean por escrito, a efectos del control administrativo del comprador o del vendedor, o a efectos de respetar leyes de control de cambios o por cualquier otra razón, siguen siendo aplicables contra una parte que haya celebrado el contrato no escrito aunque dicho contrato sea aplicable [es decir, válido] entre las partes".

\section{El principio del consensualismo y la libertad de forma ante la jurispru- dencia.}

La expresión más clara del principio del consensualismo en la Convención la encontramos en el reconocimiento a la validez de los contratos celebrados oralmente o por medio de la conducta adoptada por las partes ${ }^{8}$. Así, por ejemplo, aplicando la Convención la Corte de Apelaciones de Colonia concluyó que un contrato celebrado en virtud de un acuerdo verbal entre un vendedor cuyo establecimiento estaba en Nigeria, y un comprador alemán era perfectamente válido y la posterior carta de confirmación simplemente probaba su existencia ${ }^{9}$. Otro Tribunal, también alemán, concluyó que la prueba sobre el envío de las mercaderías por parte del vendedor y su recepción y aceptación por parte del comprador era suficiente para tener por acreditada la existencia de un contrato de compraventa entre las partes ${ }^{10}$. Del mismo modo, se ha sostenido que para celebrar válidamente un contrato de acuerdo con la Convención: "las partes no necesitan observar ningún requisito

${ }^{7}$ Naciones Unidas, Documento A/CONF.97/5 (1979), Comentarios sobre el Proyecto de Convención sobre los Contratos de Compraventa Internacional de Mercaderias, preparados por la Secretaría, p. 21.

${ }^{8}$ De acuerdo al artículo $18 \mathrm{~N}^{\circ} 1$ de la Convención, constituye aceptación: "Toda declaración u otro acto del destinatario que indique su asentimiento a una oferta". Por su parte, el $\mathrm{N}^{\circ} 3$ del mismo artículo agrega que el asentimiento del aceptante puede consistir en la ejecución de un acto como, por ejemplo, "la expedición de las mercaderías" o "el pago del precio". Así, por ejemplo, se ha fallado que la aceptación de las mercaderías por el comprador indica su asentimiento a la oferta. Véase: Oberlandsgericht Frankfurt [Corte de Apelaciones de Frankfurt, Alemania], 23 de mayo de 1995. Véase también al respecto, el artículo 29 de la Convención.

${ }^{9}$ Oberlandsgericht Köln [Corte de Apelaciones de Colonia, Alemania], 22 de febrero de 1994.

${ }^{10}$ Oberlandesgericht München [Corte de Apelaciones de Munich, Alemania], 8 de marzo de 1995. 
particular relativo a la forma de su acuerdo"11. En este mismo sentido se ha pronunciado la jurisprudencia francesa, holandesa, austríaca, norteamericana, suiza, eslovaca, etc ${ }^{12}$.

Es importante recalcar, sin embargo, que el principio del consensualismo sólo se aplica a aquellas materias reguladas por la Convención conforme a su artículo 4 (formación y efectos del contrato) y, por tanto, corresponderá a la legislación doméstica aplicable en virtud de las normas del derecho internacional privado; por ejemplo, determinar la validez de una cláusula $\operatorname{arbitral}^{13}$.

Como ya adelantamos, la Convención garantiza también la libertad de forma. El fundamento de esto radica en asegurar que las partes no se encuentren sometidas a las leyes domésticas relativas a los medios probatorios admisibles para acreditar el contrato de compraventa internacional ${ }^{14}$. En concordancia con este principio, en un reciente fallo un Tribunal norteamericano descartó aplicar la parol evidence rule a un caso regido por la Convención, señalando que, en conformidad con este estatuto: "el Tribunal no excluirá la evidencia extratextual de las negociaciones o acuerdos, como [...] las comunicaciones por correo electrónico, efectuadas con anterioridad al contrato de 2004, relativas al alcance de los derechos y obligaciones contraidos por las partes" ${ }^{15}$. Aplicando el mismo criterio, otro Tribunal norteamericano sostuvo que, de acuerdo con la Convención: "el contrato puede ser probado a través de un documento, declaraciones orales efectuadas por las partes, conductas, o una combinación de las tres"16.

Nótese que sobre la base del principio de la libertad de forma, la jurisprudencia extranjera ha aceptado como medios probatorios, entre otros: un

${ }^{11}$ Landgericht Potsdam [Tribunal de primera instancia de Potsdam, Alemania], 7 de abril de 2009.

${ }^{12}$ Véase a modo de referencia: Federal Court of Appeals for the Eleventh Circuit [Estados Unidos], 29 de junio de 1998; Oberster Gerichtshof [Corte Suprema, Austria], 6 de febrero de 1996; Rechtbank Breda [Tribunal de primera instancia de Breda, Países Bajos], 16 de enero de 2009; Tribunal de Primera Instancia de Dolny Kubin [Eslovaquia], 17 de junio de 2008; Cour d'appel Grenoble [Corte de Apelaciones de Grenoble, Francia], 28 de noviembre de 2002; Corte di Cassazione [Corte de Casación, Italia], 13 de octubre de 2006; Oberlandsgericht Graz [Corte de Apelaciones de Graz, Austria], 7 de marzo de 2002.

${ }^{13}$ Ferrari, Franco - Flechtner, Harry - Brand, Ronald A., The Draft UNCITRAL Digest and Beyond: Cases, Analysis and Unresolved Issue in the U.N. Sales Convention (Londres, Sellier European Law Publishers, 2004), p. 208.

${ }^{14}$ Ibíd., p. 212.

${ }^{15}$ Federal District Court de Pennsylvania [Estados Unidos], 29 de enero de 2010. Traducción libre del autor.

${ }^{16}$ Federal District Court de Nueva York [Estados Unidos] 21 de agosto de 2002. 
fax sin firma ${ }^{17}$, una factura junto con los documentos del transporte de las mercaderías ${ }^{18}$, telegramas y télex ${ }^{19}$, ciertas conductas adoptadas por las partes como es la apertura de una carta de crédito ${ }^{20}$, y prueba testimonial acerca de la existencia del contrato ${ }^{21}$.

La Convención, en todo caso, como bien lo ha declarado la doctrina ${ }^{22} \mathrm{y}$ jurisprudencia extranjera ${ }^{23}$, no establece ninguna jerarquía respecto al valor probatorio de los distintos medios de prueba. En consecuencia, corresponderá al juez que conoce de la causa, respetando las disposiciones de la Convención, valorar la prueba de acuerdo con las normas del foro ${ }^{24}$.

\section{El principio del consensualismo y la libertad de forma en el comercio internacional.}

Los principios del consensualismo y la libertad de forma han sido ampliamente acogidos en el comercio internacional. Prueba de ello encontramos en la consagración normativa de estos principios en diversos proyectos de unificación del derecho a nivel internacional. Así por ejemplo, el artículo 3.2 de los principios formulados por el Instituto Internacional para la Unificación del Derecho Privado (UNIDROIT) dispone que "[...] todo contrato queda perfeccionado, modificado o extinguido por el mero acuerdo de las partes, sin ningún requisito adicional." El artículo 1.1 del mismo estatuto señala que "[...] nada de lo expresado en estos Principios requiere que un contrato, declaración o acto alguno deba ser celebrado o probado conforme a una forma en particular. El contrato puede ser probado por cualquier medio, incluidos los testigos". Por su parte, el artículo 2:101(2) de los Principios del Derecho Europeo de los Contratos señala que "[...] el contrato no necesariamente se debe concluir ni hacer constar por escrito y no queda sujeto a ninguna otra exigencia de forma. Se puede probar su existencia por todos los medios posibles, incluida la prueba testifical." A su vez, la Cámara de Comercio Internacional (ICC por su sigla en inglés) ha destacado la importancia del principio del consensualismo en

${ }^{17}$ Handelsgericht des Kantons St. Gallen [Tribunal de Comercio], Suiza, 5 de diciembre de 1995.

${ }^{18}$ Arbitraje Compromex [México], 4 de mayo de 1993.

${ }^{19}$ Véase la decisión en Corte de Apelaciones de Helsinki [Finlandia] 26 de octubre de 2000.

${ }^{20}$ Véase Arbitraje Compromex [México], 29 de abril de 1996.

${ }^{21}$ Oberlandsgericht München [Corte de Apelaciones de Munich, Alemania], 8 de Marzo de 1995.

${ }^{22}$ Ferrari, Franco, cit. (n. 13), p. 212.

${ }^{23}$ Véase la decisión del Landgericht Memmingen [Tribunal de primera instancia, Alemania], 1 de Diciembre de 1993.

${ }^{24}$ Naciones Unidas, Compendio de jurisprudencia relativo a la Convención de las Naciones Unidas sobre los contratos de compraventa internacional de mercaderias. 
sus comentarios al artículo $11 \mathrm{CV}$., enfatizando que gran parte del comercio internacional se desarrolla sobre la base de contratos orales ${ }^{25}$.

\section{Limites al principio del consensualismo y la libertad de forma.}

Sin perjuicio de lo señalado hasta aquí, nada impide a los contratantes exigir la observancia de ciertas formalidades para la celebración del contrato de compraventa internacional. El artículo $6 \mathrm{CV}$. es claro cuando señala que "[...] las partes podrán excluir la aplicación de la presente Convención o, sin perjuicio de lo dispuesto en el artículo 12, establecer excepciones a cualquiera de sus disposiciones o modificar sus efectos". Por esta razón es perfectamente posible, por ejemplo, que las partes acuerden que el contrato no se entienda perfecto mientras no se otorgue por escrito. De hecho, es relativamente común en el comercio internacional que el oferente establezca como condición para la aceptación que ésta sea formulada por escrito ${ }^{26}$. Con todo, se ha resuelto que en estos casos es fundamental que el otro contratante esté en conocimiento de esta limitación puesto que, de lo contrario, una aceptación oral será igualmente válida para perfeccionar el contrato ${ }^{27}$. Asimismo, estimamos que las partes podrían dejar sin efecto una cláusula como la que comentamos si no obstante se acredita a partir de la conducta desplegada por ellas una intención en este sentido ${ }^{28}$.

También puede ocurrir que el principio del consensualismo sea excluido por los usos o prácticas que las partes hayan convenido o establecido entre ellas en conformidad con el artículo 9 CV. ${ }^{29}$.

Asimismo, algunos Tratados Internacionales pueden afectar al principio del consensualismo o la libertad de forma respecto a determinadas cláusulas del contrato de compraventa internacional. Por ejemplo, la "Convención

${ }^{25}$ RajSKi, Jerzi, cit. (n. 3).

${ }^{26}$ En este sentido: RajSKI, Jerzi, cit. (n. 3).

${ }^{27}$ Véase en este sentido: Oberster Gerichtshof [Corte Suprema, Austria], 6 de febrero de 1996.

${ }^{28}$ De acuerdo al artículo 8 número 3 servirá para determinar la intención de los contratantes, entre otros, el comportamiento ulterior de las partes. Así, por ejemplo, si no obstante haber acordado que el contrato no se entendería perfecto si no es otorgado por escrito las partes ejecutan sus obligaciones de conformidad con el mismo. En este sentido: RajSKI, Jerzi, cit. (n. 3).

${ }^{29}$ Esta disposición señala que "[...] las partes quedarán obligadas por cualquier uso en que hayan convenido y por cualquier práctica que hayan establecido entre ellas." El mismo artículo agrega que "[...] salvo pacto en contrario, se considerará que las partes han hecho tácitamente aplicable al contrato o a su formación un uso del que tenian o debian haber tenido conocimiento y que, en el comercio internacional, sea ampliamente conocido y regularmente observado por las partes en contratos del mismo tipo en el tráfico mercantil de que se trate". 
de Nueva York" sobre el reconocimiento y la ejecución de las sentencias arbitrales extranjeras de 1958 exige que la cláusula arbitral conste por escrito, no siendo admisible a su respecto los demás medios probatorios ${ }^{30}$.

Con todo, la excepción más importante al principio del consensualismo y la libertad de forma la encontramos en la reserva formulada por ciertos países conforme al artículo 96 en relación con el artículo $12 \mathrm{CV}$.

\section{LA RESERVA DEL ARTículo 96 CV.}

El artículo 96 en relación al artículo $12 \mathrm{CV}$. autorizan a aquellos Estados cuya legislación exija que los contratos de compraventa se celebren o se prueben por escrito, para formularle una reserva (en adelante la "reserva del artículo 96" o sencillamente la "reserva"). Con arreglo a tal reserva, "cualquier disposición del artículo 11, del artículo 29 o de la Parte II de la presente Convención que permita que la celebración, la modificación o la extinción por mutuo acuerdo del contrato de compraventa, o la oferta, la aceptación o cualquier otra manifestación de intención, se hagan por un procedimiento que no sea por escrito no se aplicará en el caso de que cualquiera de las partes tenga su establecimiento en ese Estado". El artículo $12 \mathrm{CV}$. agrega además que "[...] las partes no podrán establecer excepciones a este articulo ni modificar sus efectos". En consecuencia, esta disposición constituye una calificada excepción al principio de la autonomía de la voluntad consagrado en el artículo $6 \mathrm{CV}{ }^{31}$.

Como sabemos, las reservas son una institución de derecho internacional público que permiten a un Estado declarar su voluntad a fin de no quedar obligado por determinadas disposiciones de un Tratado que ha suscrito ${ }^{32}$. En el caso particular del artículo 96, la exclusión se refiere, fundamentalmente, a aquellas disposiciones de la Convención que reconocen los principios del consensualismo y la libertad de forma para acreditar el contrato de compraventa internacional de mercaderías.

En todo caso, y pese a la curiosa redacción de los artículos 12 y $96 \mathrm{CV}$., la verdad es que el ámbito de aplicación de la reserva no es tan amplio como

\footnotetext{
${ }^{30}$ Véase el artículo II de la "Convención de Nueva York" de 1958, según el cual el acuerdo de arbitraje debe constar por escrito.

${ }^{31} \mathrm{La}$ razón de esto se explica claramente si consideramos que el propósito de la reserva es hacer respetar los requisitos del país que la ha formulado en tanto éstos son considerados de orden público.

${ }^{32}$ De acuerdo al artículo 2 letra d) de la "Convención de Viena" de 1969 sobre el derecho de los tratados: "se entiende por 'reserva' una declaración unilateral, cualquiera que sea su enunciado o denominación, hecha por un Estado al firmar, ratificar, aceptar o aprobar un tratado o al adherirse a él, con objeto de excluir o modificar los efectos juridicos de ciertas disposiciones del tratado en su aplicación a ese Estado".
} 
pudiese parecer. En efecto, los artículos 12 y $96 \mathrm{CV}$. circunscriben el ámbito de aplicación de la reserva a los artículos 11 y 29, además de la Parte II de la Convención (es decir, a sus artículos 12 al 22) ${ }^{33}$. En consecuencia, los efectos de la reserva, a los cuales nos referiremos más adelante, se encuentran limitados, exclusivamente, a la formación del contrato, su modificación o extinción por mutuo acuerdo. Por tanto, la reserva no cubre todas las comunicaciones o avisos requeridos por la Convención ${ }^{34}$. Otras manifestaciones de voluntad, como aquella que puede efectuar una de las partes a fin de establecer un plazo para el cumplimiento de las obligaciones del otro contratante ${ }^{35}$, o especificando la naturaleza de la falta de conformidad de las mercancías ${ }^{36}$, o solicitando una reducción de los precios ${ }^{37}$, podrán ser formulados por cualquier medio siempre y cuando éstos resulten adecuados a las circunstancias del caso conforme lo dispone el artículo $27 \mathrm{CV} .^{38}$.

$\mathrm{Al}$ ratificar la Convención, nuestro país formuló la reserva del artículo 96 CV. Curiosamente, y pese al impacto de esta reserva en la aplicación de la Convención, existe escasa bibliografía a nivel internacional que se aboque a tratar esta materia. En Chile, por su parte, si bien se han publicado algunos trabajos que han tenido como objeto de análisis la Convención, ninguno de ellos se ha preocupado de precisar en detalle el sentido y alcance de la reserva formulada por nuestro país ${ }^{39}$. Esta será nuestra tarea en los siguientes párrafos.

\section{Antecedentes históricos de la reserva del artículo $96 \mathrm{CV}$.}

La reserva del artículo $96 \mathrm{CV}$. surgió originalmente como una suerte de acuerdo para lograr que aquellos Estados pertenecientes a la entonces Unión Soviética, en los cuales era común que se establecieran estrictos controles

${ }^{33}$ Véase al respecto: Naciones Unidas, Documento A/CONF.97/5, cit (n. 7), p. 21. En el mismo sentido; Rajski, Jerzi, cit. (n.3) y; SChlechtriem, Peter, Uniform Sales Law - The UN-Convention on Contracts for the International Sale of Goods (Vienna, Manz, 1986).

${ }^{34}$ En este sentido: Rajski, Jerzi, cit. (n. 3); Schlechtriem, Peter, cit. (n. 33).

${ }^{35}$ Véanse los artículos 47 y 63 de la Convención.

${ }^{36}$ Véase el artículo 39 de la Convención.

${ }^{37}$ Véase el artículo 50 de la Convención.

${ }^{38}$ Naciones Unidas, Documento A/CONF.97/5, cit (n. 7), p. 21. En el mismo sentido: RaJSKI, Jerzi, cit. (n. 3).

${ }^{39} \mathrm{Al}$ respecto véase: López Blanco, José Luis, Compraventa internacional de mercaderías (Santiago Chile, Ace Ediciones y Publicaciones S.A., 2001); PAILlás, Enrique, La compraventa internacional de mercaderias (Santiago, Chile, Editorial Jurídica. de Chile, 2006); y VIDAL, Álvaro, La protección del comprador: régimen de la Convención de Viena y su contraste con el Código Civil (Valparaíso, Ediciones Universitarias de Valparaíso, 2006). 
formales para las operaciones de comercio internacional ${ }^{40}$, adhirieran a la Convención ${ }^{41}$. De hecho, el artículo 144 de las "Bases de la legislación civil de la Unión de Repúblicas Socialistas Soviéticas y de las Repúblicas Federadas” sancionaba expresamente el incumplimiento de la forma escrita en los actos jurídicos relativos al comercio exterior con la invalidez del contrato ${ }^{42}$.

Por este motivo, durante los Travaux préparatoires de la Convención los representantes de la Unión Soviética insistieron en la necesidad de establecer algún mecanismo que les permitiera preservar dichos requisitos que a su juicio constituían disposiciones de orden público, frente al lenguaje liberal de la Convención ${ }^{43}$. La mayoría de los delegados, sin embargo, consideraban que esta clase de requisitos eran contrarios a las prácticas comerciales modernas, dada la rapidez e informalidad con las cuales éstas se desarrollan en las economías de mercado. Con todo, debido a la intención de los redactores de lograr que el Tratado fuera suscrito por el mayor número de Estados, finalmente se accedió a esta inquietud y se estableció la reserva del artículo $96 \mathrm{CV}$. tal como consta en el texto.

Además de nuestro país, la reserva del artículo $96 \mathrm{CV}$. ha sido formulada por: Argentina (1983), Hungría (1983), Bielorrusia (1989), Ucrania (1990), Rusia (1990), Lituania (1995), Letonia (1997), Paraguay (2006), Armenia (2008) y China ${ }^{44}$ (1986). La reserva de este último país tiene un lenguaje ligeramente distinto al de los demás Estados. Pese a esto, la mayor parte de la doctrina ${ }^{45}$ y jurisprudencia ${ }^{46}$ extranjera le atribuye los mismos efectos. $\mathrm{Al}$

${ }^{40}$ Las bases (también llamados principios) de la legislación civil de la Unión de Repúblicas Socialistas Soviéticas y de las Republicas Federadas es una suerte de constitución del derecho privado soviético que regía en todas las repúblicas y a cuyas normas debían adaptarse los distintos Códigos Civiles de los miembros de la Unión.

${ }^{41}$ RajSKI, Jerzi, cit. (n. 3). En el mismo sentido: HonNOLD, John, cit. (n. 5), sección $129^{\mathrm{a}}$.

${ }^{42}$ RAJSKI, Jerzi, cit. (n. 3). El autor cita además una lista de cuerpos normativos encargados de regular el comercio exterior en la ex Unión Soviética que dan cuenta de la necesidad de escriturar el contrato como un requisito para su validez. Véase también: MaRín, Pascual, El nuevo derecho civil de la Rusia Soviética: principios de la legislación civil de la U.R.S.S. promulgados el 1 de mayo de 1962 (Madrid, Instituto Editorial Reus, 1963), p. 16.

${ }^{43}$ HonnOLD, John, cit. (n. 5), sección 128 a.

44 “The People's Republic of China does not consider itself bound by [...] article 11 as well as the provision of the Convention relating to the content of article 11".

${ }^{45}$ Entre otros: YANG, Fan. The Application of the CISG in the Current PRC Law and CIETAC Arbitration Practice, en Nordic Journal of Commercial Law, 2 (2006); y Wang, Xiaolin - Andersen, Camila. The Chinese Declaration against Oral Contracts under the CISG., en Vindobona Journal of International Commercial Law \& Arbitration, 8 (2004).

${ }^{46}$ Véase el caso: China International Economic \& Trade Arbitration Commission (CIETAC), China, 15 de diciembre de 1997. 
ratificar la Convención, Estonia también formuló esta reserva pero la retiró el año $2004^{47}$.

Como se observa de esta lista de países, salvo ciertas excepciones, la mayoría de ellos proviene de regímenes socialistas caracterizados por establecer estrictos controles formales para las operaciones de comercio exterior. En estos países la reserva ha cumplido con el objetivo para el cual fue concebida, evitando que los requisitos formales relativos a la escrituración del contrato, se vean anulados por las disposiciones de la Convención que garantizan la libertad de forma y el principio del consensualismo en el contrato de compraventa internacional. Con todo, aun en ellos podemos encontrar voces disidentes que abogan por su eliminación ${ }^{48}$.

\section{Marco jurídico de las reservas autorizadas por la "Convención".}

Si bien la Convención permite a los Estados Contratantes formular declaraciones o reservas a fin de excluir la aplicación de determinadas disposiciones del Tratado, esta facultad se encuentra restringida, únicamente, a aquellas reservas contempladas por la Convención en sus artículos 92 a $96 \mathrm{CV}$. En efecto, el artículo $98 \mathrm{CV}$. es categórico al señalar que: “[... ] no se podrán hacer más reservas que las expresamente autorizadas por la Convención”.

Del mismo modo, y atendido su carácter excepcional, en caso de formular una de estas reservas, el Estado contratante respectivo deberá sujetarse estrictamente a los términos y condiciones establecidos por el tratado a estos efectos ${ }^{49}$. Por consiguiente, si la reserva exige el cumplimiento de determinados requisitos, el Estado que la pretenda formular deberá estarse a ellos. Este es precisamente el caso de las reservas de los artículos 93, 94 y 96.

Pues bien, al ratificar la "Convención de Viena" nuestro país formuló la reserva del artículo $96 \mathrm{CV} .{ }^{50}$. De acuerdo con lo dispuesto en este artículo, sólo están autorizados para formular esta declaración aquellos Estados “cuya legislación exija que los contratos de compraventa se celebren o se prueben por escrito". Este requisito es de toda lógica toda vez que, como hemos dicho, la finalidad de la reserva es precisamente proteger aquellas normas del de-

${ }^{47}$ Véase la situación de la Convención en los distintos países en: http://www.uncitral.org/uncitral/en/uncitral_texts/sale_goods/1980CISG_status.html

${ }^{48}$ Wang, Xiaolin y Andersen, Camila, cit. (n. 45).

${ }^{49}$ Véase al respecto los artículos 19 y siguientes de la "Convención de Viena" de 1969 sobre el Derecho de los tratados.

50 "El Estado de Chile declara, en conformidad con los artículos 12 y 96 de la Convención, que cualquier disposición del artículo 11, del artículo 29 o de la Parte II de la Convención que permita que la celebración, la modificación o la terminación por mutuo acuerdo del contrato de compraventa o cualquier oferta, aceptación u otra manifestación de intención se hagan por cualquier procedimiento que no sea por escrito, no se aplicará en el caso de que cualquiera de las Partes tenga su establecimiento en Chile". 
recho doméstico de un Estado contratante que exigen la escrituración del contrato, ya sea como requisito de forma o prueba, y que, en ausencia de la reserva, se verían desplazadas por las disposiciones de la Convención que establecen la informalidad del contrato y que, atendido su carácter de lex specialis, se deben aplicar con preferencia. De no existir tales normas, la reserva simplemente carecería de toda utilidad toda vez que no habría normas que proteger a través de ella. Por esta razón, la doctrina extranjera ha visto en este requisito una suerte de condición habilitante para poder formular válidamente la reserva ${ }^{51}$.

En este orden de ideas, a continuación examinaremos las diversas interpretaciones que ha suscitado la reserva del artículo $96 \mathrm{CV}$. en la doctrina y jurisprudencia tanto nacional como extranjera.

\section{Alcance y efectos de la reserva del artículo $96 \mathrm{CV}$. según la doctrina} extranjera.

En general, la doctrina y jurisprudencia extranjera está de acuerdo en que el efecto inmediato de la reserva es excluir o dejar sin aplicación aquellas disposiciones de la Convención que permiten que el contrato se celebre o se pruebe por escrito. Las divergencias, empero, surgen a la hora de determinar la legislación que debemos aplicar en reemplazo de aquellas normas excluidas. Como veremos, además, los autores dan por sentado que la legislación doméstica del Estado reservatario efectivamente exige que los contratos de compraventa se celebren o se prueben por escrito. Veamos.

Una primera posición sostiene que basta con que cualquiera de las partes tenga su establecimiento en un Estado que haya formulado la reserva para que los requisitos de forma de dicho Estado -en tanto se relacionen con la exigencia de escrituración del contrato y no otros requisitos adicionales ${ }^{52}$ le sean aplicables automáticamente y con prescindencia de las normas del derecho internacional privado ${ }^{53}$. Si bien esta interpretación pudiese parecer

${ }^{51}$ Entre otros: Ferrari, Franco, cit. (n. 13), pp. 213-214; YANG, Fan, cit. (n. 44); y Schroeter, Ulrich. Backbone or Backyard of the Convention? The CISG's Final Provisions, en EL MISMO, Sharing International Commercial Law across National Boundaries (Wildy, Simmonds \& Hill Publishing, 2008).

${ }^{52}$ Schlechtriem, Peter, Uniform Sales Law - The UN-Convention on Contracts for the International Sale of Goods (Vienna, Manz, 1986); y Honnold, John, cit. (n. 5), sección $129^{\mathrm{a}}$.

${ }^{53}$ En este sentido: Winship, Peter. The Scope of the Vienna Convention on International Contracts, en GALSTON, N. - SMIT, H. (editores), International Sales: The United Nations Convention on Contracts for the International Sale of Goods (Matthew Bender, 1984), pp. 1-53. Véase también: HonNOLD, John, cit. (n. 5), sección 129ª En cuanto a la jurisprudencia extranjera, véase: Tribunal de Arbitraje Comercial Internacional de la Cámara de Comercio e Industria de la Federación Rusa, 16 de febrero de 2004. 
razonable a la luz del confuso lenguaje empleado por los artículos 12 y 96 $\mathrm{CV}$., presenta una importante objeción de acuerdo a la historia legislativa de la Convención. Como bien señala el delegado de Polonia, profesor Jerzi Rajski, durante los Travaux préparatoires se propuso reformular el lenguaje de la reserva acorde con esta interpretación, lo cual, sin embargo, no prosperó. La propuesta fue rechazada por cuanto se estimó que su adopción haría aplicables más allá de lo razonable los requisitos formales del Estado reservatario y excluiría además las normas de derecho internacional privado del foro, sin que el Estado donde éste se encuentra ubicado haya consentido en ello ${ }^{54}$.

Para ilustrar los efectos de la reserva conforme a esta interpretación, analizaremos a continuación un ejemplo. Supongamos que un exportador (en adelante "E") cuyo establecimiento se encuentra en Chile celebra por teléfono un contrato de compraventa internacional para el suministro de determinados bienes a un "retailer" (en adelante "R") cuyo establecimiento se encuentra en EE. UU. (país que no ha formulado la reserva de artículo $96 \mathrm{CV}$.). En este caso, y de acuerdo a la interpretación recién examinada, el contrato quedará sujeto en principio a los requisitos de forma de nuestro país, aun cuando el foro no se encuentre en Chile, y con prescindencia del lugar de su celebración o cualquier otro factor de conexión del derecho internacional privado. Más adelante nos referiremos a los requisitos que deberá cumplir el contrato en una situación como esta.

Una segunda posición -mayoritaria por lo demás-, y a la cual adherimos, sostiene que el mero hecho de que una de las partes tenga su establecimiento en un Estado reservatario no significa necesariamente que los requisitos de forma de dicho Estado deban ser aplicados al contrato. Por el contrario, dependerá de las normas del derecho internacional privado del foro determinar si ha de observarse algún requisito de forma ${ }^{55}$. Por consiguiente, cuando estas normas se remitan a la legislación de un Estado que ha formulado la reserva, los requisitos de forma de dicho Estado relativos a la escrituración del contrato deberán ser aplicados en reemplazo de las normas de la Convención excluidas $^{56}$. Si la norma de conflicto, en cambio, se remite a la legislación de

${ }^{54}$ RAJSKi, Jerzi, cit. (n. 3).

${ }^{55}$ Schlechtriem, Peter, cit. (n. 52); Ferrari, Franco, cit. (n. 13), pp. 213-214; Lookofsky, Joseph M., The 1980 United Nations Convention on Contracts for the International Sale of Goods, en J. HeRbots, J. - BlanPAIN, R. (editores). International Encyclopedia of Laws Contracts (La Haya, Kluwer Law International, Suppl. 29 de Diciembre de 2000); y Perales Viscasillas, María del Pilar. El contrato de compraventa internacional de mercancías ("Convención de Viena" de 1980). En Chile véase: Paillás, Enrique, cit. (n. 39), p. 37. Si bien este último autor no toma partido cita al profesor Claude Witz quien adhiere a esta postura.

${ }^{56}$ Rechtbank Rotterdam [Tribunal de Primera Instancia de Rotterdam, Países Bajos], 12 de julio de 2001 . 
un Estado no reservatario, se nos abren nuevamente dos alternativas según consideremos para estos efectos que la Convención forma parte de la legislación de dicho Estado o no. Si consideramos que forma parte, el contrato no estará sujeto a requisito de forma alguno ya que será plenamente aplicable lo dispuesto en el artículo $11 \mathrm{CV} .{ }^{57}$. Si concluimos lo contrario, en cambio, al contrato le serán aplicables los requisitos de forma o prueba de la legislación doméstica no uniforme del Estado no reservatario ${ }^{58}$.

Volvamos a nuestro ejemplo. Si adoptamos esta interpretación, habrá que analizar las normas de derecho internacional privado del foro para determinar la legislación aplicable a esta materia. Suponiendo que el foro se encuentra en Chile, debemos aplicar el principio lex locut regit actum como se desprende del artículo $14 \mathrm{CCCh}$. En consecuencia, los requisitos de forma del contrato estarán sujetos a la ley del lugar de su celebración ${ }^{59}$. Dado que la Convención sólo precisa el momento en el cual el contrato se perfecciona mas no el lugar donde éste debe entenderse celebrado ${ }^{60}$, tendremos que

${ }^{57}$ En este sentido: Schlechtriem, Peter, cit. (n. 52); Perales Viscasillas, María del Pilar, cit. (n.55); y Adame Goddard, Jorge, Análisis de un dictamen de la Compromex sobre un caso de compraventa Internacional, en Revista de Derecho Privado, Nueva Serie, 1 (2002). Véase también: Hooge Raad [Corte Suprema, Holanda], 7 de noviembre de 1997.

${ }^{58}$ En este sentido: Flechtner, Harry, The Several Texts of the CISG in a Decentralized System: Observations on Translations, Reservations and other Challenges to the Uniformity Principle in Article 7(1), en Journal of Law and Commerce, 17 (1998).

${ }^{59}$ Ramírez, Mario. Análisis crítico del Derecho internacional privado chileno (Santiago, LexisNexis, 2007).

${ }^{60}$ De acuerdo a los Comentarios sobre el Proyecto de Convención sobre los contratos de compraventa internacional de mercaderías, preparados por la Secretaría, cit. (n. 7), la Convención: "no incluye norma expresa respecto del lugar en que se celebra el contrato." Sin embargo, "el hecho de que en el articulo 21 (hoy artículo 23), en relación al artículo 16 (hoy articulo 18), se fije el momento en que se celebra el contrato puede interpretarse en algunos sistemas jurídicos, como si determinara el lugar de celebración”. De hecho, a lo menos un Tribunal llegó a esta conclusión, véase al respecto: Federal Court, South Australian District [Adelaide, Australia], 28 de Abril de 1995. En nuestra opinión, sin embargo, el lugar de celebración es claramente una cuestión no resuelta por la Convención ni puede ser resuelta por los principios que la informan; por lo que, de acuerdo al artículo 7(2) de la misma, deberá resolverse "de conformidad con la ley aplicable en virtud de las normas de derecho internacional privado". Para igual conclusión, véase: PErales Viscasillas, María, Comments on the draft Digest relating to Articles 14-24 and 66-70, en Ferrari, Franco, cit. (n. 13), pp. 281-282. Sin ir más lejos, en Chile el lugar de celebración del contrato no puede inferirse necesariamente del momento de su celebración. En efecto, los artículos 99 y 101 CCom. acogen la teoría de la declaración para determinar el momento en que la aceptación produce sus efectos mientras que el artículo 104 del mismo cuerpo legal señala que el lugar de celebración del contrato corresponde al de la residencia del aceptante sin que importe donde éste haya declarado 
estarnos a estos efectos a lo dispuesto en el artículo 104 CCom. De acuerdo a esta disposición el contrato se entiende celebrado en el lugar de residencia del aceptante cuando este y el destinatario tengan su residencia en lugares distintos. De esta forma, si la aceptación es formulada por $\mathrm{R}$ el contrato quedará sujeto, en cuanto a sus requisitos de forma o prueba, a la legislación de EE.UU., puesto que R tiene su establecimiento, y presuntamente su residencia en dicho Estado.

En esta hipótesis surge el problema que habíamos advertido anteriormente en cuanto a la determinación de la ley aplicable. Según se siga una u otra posición la ley aplicable será: ya sea la "Convención de Viena" como parte de la legislación doméstica de EE.UU., lo que importa además aplicar el artículo $11 \mathrm{CV}$. y con ello el principio de la libertad de forma; o la legislación doméstica no uniforme de EE.UU, vale decir, el Uniform Commercial Code. En este último caso, sin embargo, se daría la paradoja de aplicar el Statute of frauds $s^{61}$ norteamericano y descartar con ello que en nuestro ejemplo se haya celebrado válidamente un contrato, aun cuando EE. UU. no formuló la reserva del artículo $96 \mathrm{CV}$., demostrando con ello su voluntad de reconocer los contratos celebrados oralmente.

Creemos que esta solución puede conducir, como de hecho ocurre en nuestro ejemplo, a consecuencias absurdas haciendo aplicable al contrato requisitos formales que jamás pretendieron ser introducidos dentro del régimen de la "Convención de Viena"; ni por el Estado reservatario, puesto que no son sus propios requisitos, ni por el Estado no reservatario, que voluntariamente renunció a ellos al ratificar la Convención sin formular la reserva del artículo $96 \mathrm{CV}$. Por este motivo, estimamos preferible aplicar en estos casos la "Convención de Viena" como parte integrante de la legislación del respectivo Estado al cual se remite la norma de conflicto y de esta manera garantizar la libertad de forma consagrada en el artículo $11 \mathrm{CV}$.

Ahora bien, si la norma de conflicto se remite a la legislación chilena, habrá que examinar nuestro derecho doméstico a fin de determinar los requisitos de forma o prueba que tendremos que aplicar al contrato de compraventa en reemplazo de las normas de la Convención excluidas por la reserva. Nótese que este mismo ejercicio tendrán que hacer aquellos que consideren que el efecto de la reserva es hacer automáticamente aplicables los requisitos de forma o prueba del Estado reservatario.

su aceptación (lo cual perfectamente puede ocurrir estando éste en un lugar distinto al de su residencia).

${ }^{61}$ Véase el artículo $\$ 2-201$ del UCC. 
4. Requisitos formales aplicables al contrato de compraventa según la legislación chilena.

En lo que concierne a la validez del contrato, nuestra legislación nacional no ha establecido requisito de forma alguno que el contrato de compraventa deba cumplir. Por el contrario, nuestra legislación ha reconocido expresamente su carácter consensual, como lo demuestra el artículo $1801 \mathrm{CCCh}$., cuando dispone que "[...] la venta se reputa perfecta desde que las partes han convenido en la cosa y en el precio"62. A partir de este momento, nace el contrato sin que sea necesario para ello la entrega de la cosa, el pago del precio o el cumplimiento de ulterior solemnidad ${ }^{63}$.

Sin perjuicio de esto, es cierto que existen excepciones a esta regla, tales como la compraventa de bienes raíces, naves, las ventas forzosas, entre otras. Sin embargo, estos casos se encuentran fuera del ámbito de aplicación de la Convención y, por tanto, mal podríamos aplicar las solemnidades establecidas en ellos al contrato de compraventa internacional de mercaderías. En consecuencia, descartamos desde ya que, a consecuencia de la reserva, el contrato de compraventa internacional esté sujeto a la observancia de alguna solemnidad relativa a su escrituración como requisito para su validez.

Ahora bien, tratándose de la prueba del contrato, creemos que el efecto de la reserva dependerá, en definitiva, del carácter civil o comercial del acto para las partes. De este modo, si el contrato de compraventa internacional es además constitutivo de un acto de comercio, tendremos que aplicar las normas del Código mercantil a esta materia. En caso contrario, habrá que estarse a lo dispuesto a estos efectos por el derecho común.

En nada obsta a esta conclusión el que el artículo $1 \mathrm{~N}^{\circ} 3 \mathrm{CV}$. disponga que "[a] los efectos de determinar la aplicación de la presente Convención, no se tendrán en cuenta ni la nacionalidad de las partes ni el carácter civil o comercial de las partes o del contrato" puesto que esta disposición excluye la mercantilidad del acto como un criterio relevante para determinar la aplicación de la Convención. En este caso, en cambio, la mercantilidad del acto es un criterio para determinar la legislación aplicable en reemplazo de las normas de la Convención excluidas. Veamos entonces.

Pues bien, al tratar esta materia el artículo 128 CCom. señala que “[...] la prueba de testigos es admisible en negocios mercantiles, cualquiera que sea la cantidad que importe la obligación que se trate de probar, salvo los casos en que la ley exija escritura pública". Por su parte, el artículo 129 CCom. establece que "[...] los juzgados de comercio podrán, atendidas las circunstancias de la

${ }^{62}$ Artículo 1801. Véase también artículo 1443 CCCh.

${ }^{63}$ Véase por ejemplo: Alessandri, Arturo. De los contratos (Santiago, Editorial Jurídica de Chile, 1994). 
causa, admitir prueba testimonial aun cuando altere o adicione el contenido de las escrituras públicas". Se sigue de estos artículos, entonces, que en materia mercantil nuestra legislación no sólo acepta y reconoce plenamente el principio del consensualismo sino también el de la libertad de forma.

En consecuencia, dado que nuestro Código de Comercio no ha establecido exigencias especiales respecto a la prueba del contrato, ni contiene limitaciones particulares en cuanto a la admisibilidad de los medios probatorios, debemos concluir, entonces, que en todos aquellos casos en los cuales concurran respecto al contrato de compraventa internacional regulado por la Convención criterios de mercantilidad reconocidos en nuestra legislación comercial, el contrato no estará sujeto a ninguna restricción especial en lo que se refiere a su prueba, aun cuando nuestro país haya formulado la reserva del artículo $96 \mathrm{CV}$.

Ahora bien, la situación es distinta si el acto es civil. En efecto, en esta hipótesis tendremos que estarnos a lo dispuesto en el Código del ramo y, en particular, a los artículos 1708 y 1709 CCCh. para determinar los efectos prácticos de la reserva.

Pues bien, de acuerdo con el artículo 1708 CCCh.: "[...] no se admitirá prueba de testigos respecto de una obligación que haya debido consignarse por escrito". Por su parte, el artículo 1709 CCCh. precisa que: "[...] deberán constar por escrito los actos o contratos que contienen la entrega o promesa de una cosa que valga más de dos unidades tributarias". Agrega la misma disposición en su inciso segundo que: "[...] no será admisible la prueba de testigos en cuanto adicione o altere de modo alguno lo que se exprese en el acto o contrato, ni sobre lo que se alegue haberse dicho antes, o al tiempo o después de su otorgamiento, aun cuando en algunas de estas adiciones o modificaciones se trate de una cosa cuyo valor no alcance a la referida suma."

A diferencia de lo que algunos pudiesen pensar, estas disposiciones no exigen que el contrato sea probado necesariamente por escrito sino que tan solo excluyen la admisibilidad de la prueba testimonial como un medio directo para acreditar su existencia o modificación. En consecuencia, estimamos que cuando la legislación civil resulte aplicable a esta materia el efecto práctico de la reserva será simplemente excluir la prueba testimonial como medio directo para acreditar la existencia, modificación o terminación del contrato de compraventa internacional regulado por la Convención, en los términos establecidos en los artículos 1708 y 1709 CCCh.

5. Comentarios respecto a la justificación de la reserva de acuerdo a nuestra legislación doméstica.

Pese a la falta de historia legislativa del establecimiento de la reserva en Chile, todo parece indicar que la declaración formulada por nuestro 
país encuentra su justificación en la diferencia existente entre el régimen de prueba contemplado en la Convención y aquel establecido por nuestra legislación civil ${ }^{64}$.

Ahora bien, no resulta del todo claro que una justificación como ésta sea aceptable desde la órbita de la Convención. En efecto, de acuerdo al artículo 96 sólo están autorizados para formular esta reserva aquellos Estados "cuya legislación exija que los contratos de compraventa se celebren o seprueben por escrito". En Chile, en cambio, aun cuando se encuentra excluida la prueba testimonial, conforme lo hemos señalado, no es necesario que el contrato se pruebe exclusivamente por escrito o, en otras palabras, a través de prueba instrumental. Por el contrario, es perfectamente posible acreditar el contrato de compraventa y las obligaciones que de él nacen, a través de otros medios probatorios, tales como la confesión judicial, sin que sea imprescindible contar con prueba instrumental.

Por otra parte, ni siquiera la exclusión de la prueba testimonial es absoluta pues el mismo artículo $1711 \mathrm{CCCh}$. admite su procedencia, cualquiera sea la cuantía del acto, cuando haya sido imposible obtener una prueba escrita o cuando exista un principio de prueba por escrito. Luego, aun fuera de estas hipótesis, a nuestro juicio, y tal como señalamos precedentemente, los artículos 1708 y $1709 \mathrm{CCCh}$. sólo excluyen la prueba testimonial como medio directo para acreditar el contrato mas no impiden que las partes puedan valerse de este medio probatoria para acreditar la existencia de determinados hechos que puedan servir de base para presunciones judiciales y, por esta vía, obtener que el tribunal de por probada la existencia, modificación o terminación del contrato de compraventa internacional ${ }^{65}$.

Tampoco pareciera ser ésta una materia de orden público que justifique ser protegida mediante una reserva. Así, por ejemplo, la jurisprudencia ha sostenido que "[...] el artículo 1709 CCCh. [...] no es probibitivo, sino meramente reglamentario de la testifical. Es así como el propio Código Civil la acepta en casos expresos. Tampoco se trata de una norma de orden público, porque el legislador, que es uno solo, estatuye un principio diverso en el Código de Comercio, en que la regla general es la procedencia de la prueba de testigos, sin que sea concebible que atentare contra su propio orden público"66.

$\mathrm{Si}$ a esto sumamos que buena parte de los Estados que ratificaron la Convención sin formular esta reserva, disponen en sus respectivas legislaciones domésticas la exclusión de la prueba testimonial para acreditar los contratos

\footnotetext{
${ }^{64}$ Según Paillás esta sería aparentemente la razón. Sin embargo, el citado autor no cita ninguna fuente.

${ }^{65}$ A modo de ejemplo se puede ver: Corte de Apelaciones de Santiago, 29 de octubre de 1980, en Revista de Derecho y Jurisprudencia, 77 (1980), sección 2a a p. 163.

${ }^{66}$ Corte Suprema, 18 de mayo de 1961, en Revista de Derecho y Jurisprudencia, 58, sección $1^{\text {a }}$, p. 132.
} 
de compraventa que excedan de cierto valor ${ }^{67}$, la justificación de nuestro país se torna aún más cuestionable. En efecto, es posible suponer que si estos Estados no formularon esta reserva, fue seguramente en el entendido de que una norma de esta naturaleza no los habilitaba para ello.

A lo anterior cabe agregar que la doctrina extranjera ha señalado que para que un determinado Estado esté habilitado para formular esta reserva es necesario que los requisitos del artículo $96 \mathrm{CV}$. sean exigidos por la legislación doméstica de dicho Estado a todos los contratos de compraventa y no sólo a ciertas categorías ${ }^{68}$. En Chile, en cambio, los únicos "requisitos" que podemos encontrar son las limitaciones a la admisibilidad de la prueba testimonial contenidas en el Código Civil; y ni siquiera ellas se aplican de forma general sino sólo en aquellos casos en los cuales el contrato de compraventa internacional no esté sujeto, en lo que respecta a su prueba, a la legislación mercantil conforme lo hemos señalado.

Atendido todo anterior, más de alguno podría concluir que la legislación chilena simplemente no cumple con las condiciones necesarias para habilitar a nuestro país para formular la reserva del artículo $96 \mathrm{CV} \cdot{ }^{69}$. Enfrentados a una situación como ésta, algunos autores extranjeros han postulado que corresponde a los tribunales declarar derechamente la invalidez de la reserva al conocer de un asunto en que ella tenga incidencia ${ }^{70}$.

Sin perjuicio de lo que hemos señalado hasta aquí, no estamos de acuerdo con esta postura pues no existe disposición alguna en la Convención que permita a un tribunal calificar el cumplimiento por parte de un Estado reservatario de los requisitos del artículo 96. Por el contrario, la misma Convención en su artículo $97 \mathrm{~N}^{\circ} 4$ establece el procedimiento a seguir para dejar sin efecto esta reserva sin contemplar la posibilidad de que sean los tribunales quienes realicen esta tarea $^{71}$. En consecuencia, mientras la reserva no sea retirada

${ }^{67}$ Véase la sección 2-201 del UCC de Estados Unidos, el artículo 1341 CC. francés y el artículo 2721 CC. italiano, entre otros.

${ }^{68}$ Schroeter, Ulrich, Backbone or Backyard of the Convention? The CISG's Final Provisions en El MiSmo, Sharing International Commercial Law Across National Boundaries (Wildy, Simmonds \& Hill Publishing, 2008), quien cita además a: Alejandro Garro, Peter Schlechtriem y Jersi Rajzki.

${ }^{69}$ Se ha presentado un problema similar a propósito de la reserva formulada por China ya que tras la reforma del año 1999 de su derecho uniforme de los contratos es posible actualmente celebrar válidamente contratos de forma oral o por cualquier otro medio. Al respecto, véase: Oberster Gerichtshof [Corte Suprema, Austria], 17 de diciembre de 2003.

${ }^{70}$ Véase al respecto: SCHroeter, Ulrich, cit. (n. 68), p. 436.

${ }^{71}$ De acuerdo al numeral 4 del artículo 97: “[...] todo Estado que haga una declaración conforme a la presente Convención podrá retirarla en cualquier momento mediante notificación formal hecha por escrito al depositario". 
formalmente, conforme al procedimiento establecido para estos efectos por el Tratado, debemos aceptar que ésta continúa plenamente vigente.

Ahora bien, así las cosas, es importante que la reserva sea interpretada correctamente; es decir, de forma coherente y consistente con nuestra legislación domestica de modo que sus efectos se encuentren restringidos a excluir la admisibilidad de la prueba testimonial en los casos en los cuales el legislador chileno lo ha hecho (a saber, cuando el contrato de compraventa pueda ser calificado de civil). Sólo en estos casos podría colegirse que existe un interés legítimo en conservar las disposiciones de derecho interno evitando así que sean desplazadas por las normas de la Convención que admiten toda clase de medios probatorios para acreditar el contrato de compraventa internacional. Veremos a continuación, sin embargo, que la doctrina y jurisprudencia nacional ha atribuido a la reserva un alcance muy distinto al que hemos postulado, llegando incluso a sostener que el contrato de compraventa internacional de mercaderías debe considerarse solemne en Chile producto de la reserva.

6. Análisis crítico de las interpretaciones propuestas por la doctrina nacional a la reserva del artículo 96

En nuestro país no son muchos los autores que se han referido a los efectos de la reserva del artículo 96. Luego, los que sí lo han hecho proponen interpretaciones que se alejan notablemente de aquellas que gozan de mayor aceptación en la doctrina y jurisprudencia extranjera y que analizamos precedentemente. A continuación trataremos estas interpretaciones.

a) Sandoval. Para este autor ${ }^{72}$, el efecto de la reserva del artículo 96 es el de excluir totalmente la aplicación de la parte II de la Convención relativa a la formación del contrato (artículo 14 a 24). En efecto, el autor señala que la "segunda parte de la 'Convención de Viena' de 1980 puede excluirse totalmente de aplicación mediante una declaración ad hoc efectuada por los Estados al momento de hacerse partes de dich a Convención". Agrega el autor que: "[...] el mecanismo de exclusión o reserva se basa en los artículos 12 y 96 del texto uniforme". De este modo "cuando el establecimiento de uno de los contratantes se encuentre radicado en alguno de los Estados que hayan realizado la referida declaración, el contrato de compraventa internacional de mercaderias celebrado estará sometido a la aludida Convención, excepto en lo relativo a su perfeccionamiento, materia que será regida por el derecho nacional que resulte aplicable conforme a las reglas del Derecho internacional privado".

Estamos en desacuerdo con esta interpretación. Como señaláramos

${ }^{72}$ Sandoval, Ricardo, Los contratos mercantiles (Santiago, Editorial Jurídica, 2003), I, pp. 259-260. 
precedentemente, el efecto de la reserva con arreglo a los artículo 12 y 96 CV. no es el de excluir por completo la parte II de la Convención, sino sólo aquellas disposiciones que permitan que la celebración, la modificación o la terminación por mutuo acuerdo se haga por un procedimiento que no sea por escrito. De este modo, las normas de la Convención sobre su formación y que, por ejemplo, requieren de una oferta y una aceptación para que el contrato se entienda celebrado, subsistirán plenamente aplicables en todo aquello que no pugnen con lo dispuesto en los artículos 12 y $96 \mathrm{CV}$. De hecho, el concluir lo contrario importaría confundir la reserva del artículo 96 con la del artículo $92 \mathrm{CV}$., que permite a los Estados signatarios excluir la aplicación de la parte II o la parte III de la Convención. Esta reserva no ha sido formulada por nuestro país y por ende no corresponde aplicarla bajo la forma del artículo $96 \mathrm{CV}$.

Creemos que este es precisamente el error en el que incurre Sandoval. De hecho, al referirse a esta materia el autor enumera una serie de Estados que al 30 de enero de 1991 habían formulado esta reserva, confundiendo dentro del mismo grupo a aquellos que habían formulado la reserva del artículo $96 \mathrm{CV}$. con aquellos que habían formulado la declaración del artículo $92 \mathrm{CV} .^{73}$.

b) Lopez Blanco. El profesor López Blanco ${ }^{74}$ también se ha referido a esta materia. A su juicio: "para que un contrato de compraventa internacional de mercaderias tenga valor en Chile se requiere, de acuerdo con la disposición recién transcrita [artículo $96 \mathrm{CV}$.], que dicho contrato conste por escrito". Todo parece indicar que este autor se refiere al término valor como sinónimo de validez. Esta conclusión, además, se ve corroborada cuando el autor afirma que a causa de la reserva del artículo 96, que: "en lo que se refiere al contrato de compraventa internacional, sujeto a las disposiciones de la 'Convención de $V$ iena', la norma chilena no permite que el contrato se entienda perfecto sin que constepor escrito". En consecuencia, según este autor, y producto de la reserva, el contrato de compraventa internacional de mercaderías sujeto a la Convención debe considerarse solemne ${ }^{75}$. Con todo, el mismo autor agrega que: "[...] no se requiere a este efecto ninguna solemnidad especial; basta, simplemente, que los términos del referido convenio, consten, de alguna manera, por escrito;

${ }^{73}$ SAndoval, Ricardo, cit. (n. 72), p. 260.

${ }^{74}$ López Blanco, José Luis, cit. (n. 39), pp. 65-66.

${ }^{75}$ Para una conclusión similar, véanse los siguientes fallos: Alto Tribunal Arbitral de la Federación de Rusia, Arbitraje, 25 de marzo de 1997; Federal District Court de Nueva Jersey, 7 de octubre de 2008; y Federal District Court de Florida, 19 de mayo de 2008. Un caso interesante que involucró a una parte cuyo establecimiento estaba situado en Chile podemos encontrar en: Rechtbank van Koophandel [Tribunal de Primera Instancia, Hasselt, Bélgica], 2 de mayo de 1995. 
sea, en un solo documento, suscrito por ambas partes; o, también, a través de intercambio de correspondencia en que consten la oferta y su aceptación".

Tampoco estamos de acuerdo con esta interpretación. El propósito de esta reserva no es erigirse como un requisito adicional a los contemplados por la legislación del Estado reservatario, sino proteger los requisitos de forma o prueba ya existentes en dicho Estado, haciéndolos aplicables al contrato; no obstante las disposiciones de la Convención que establecen la informalidad del mismo y que, en ausencia de la reserva, desplazarían a estos requisitos dejándolos sin aplicación. En este sentido, debe recordarse que es a causa de la legislación doméstica de un Estado que no reconoce el principio del consensualismo o la libertad de forma para acreditar el contrato, que la reserva impide que el contrato de compraventa internacional sea celebrado por un procedimiento que no sea por escrito, no al revés. En consecuencia, si el contrato de compraventa en Chile es consensual, la reserva simplemente no puede ser interpretada de modo que constituya una excepción a esta regla puesto que, por sí sola, tan solo excluye la aplicación de ciertas disposiciones de la Convención sin transformar automáticamente al contrato en solemne. Esto último, en definitiva, dependerá de la legislación que resulte aplicable en esta materia conforme a las normas de derecho internacional privado del foro. De este modo, si la legislación aplicable es la chilena, tendremos que estarnos a lo dispuesto en el artículo 1801 CCCh., que establece expresamente la consensualidad de la compraventa, sea ésta civil o mercantil, y, en consecuencia, el contrato de compraventa internacional no estará sujeto a solemnidad alguna que exija su escrituración como requisito de validez.

Tampoco puede estimarse que el legislador chileno haya pretendido hacer una excepción a la consensualidad del contrato de compraventa internacional mediante la formulación de esta reserva. Para ello, y sin perjuicio de que semejante interpretación es abiertamente contraria a la finalidad de la reserva, tendría que haber existido una razón que justificara aplicar a los contratos de compraventa internacional regulados por la Convención una regla distinta a aquella que rige para los contratos de compraventa internos y los internacionales que escapen del ámbito de regulación de la Convención ${ }^{76}$. Tal razón, sin embargo, no existe.

${ }^{76}$ Dado su ámbito de aplicación y, en particular, el criterio de internacionalidad escogido por la ley uniforme, es perfectamente posible que un contrato de compraventa sea calificado como internacional en nuestro país aun cuando escape del campo de aplicación de la Convención. Si las partes no han sujetado este contrato a una legislación en particular, el juez deberá hacer uso de las normas de derecho internacional privado para determinar el derecho aplicable. Suponiendo que esas normas apuntan a la legislación chilena, tendríamos que aplicar el artículo $1801 \mathrm{CCCh}$. por lo que se nos daría la paradoja de que este contrato de compraventa internacional sería consensual, al igual que el 
En suma, estimamos que la interpretación de López Blanco debe ser descartada en atención a las razones expuestas precedentemente.

c) Maluenda. Maluenda ${ }^{77}$, por su parte, también se ha pronunciado respecto a los efectos de la reserva en comento. Al referirse a este tema el autor sostiene en su obra que existen a lo menos dos formas de interpretar la reserva del artículo $96 \mathrm{CV}$. Una de ellas es considerar que a causa de la reserva "las normas de la Convención que establecen que la compraventa internacional es consensual, no se aplicarán, por lo que debería aplicarse las disposiciones internas correspondientes". Atendido el reconocimiento al principio del consensualismo en nuestro derecho doméstico, el autor concluye que "en este caso, no habria ninguna diferencia entre la compraventa interna e internacional, relativo al modo en que se perfecciona”.

La otra interpretación posible según Maluenda, y a la cual él adhiere, es aquella que sostiene que producto de la reserva del artículo $96 \mathrm{CV}$.: "la oferta, la aceptación, la celebración, la modificación o la terminación del contrato de compraventa internacional, deberán hacerse por escrito cuando cualquiera de las partes tenga su establecimiento en Chile." En este caso -señala el autor-: "[...] existiria una diferencia de trascendencia en materia de compraventa. Si ella es internacional, siempre deberia dejarse constancia por escrito, y si es interna, en cambio, sólo en ciertos casos". Los casos a los cuales se refiere el autor son aquellos que resultan de distinguir la compraventa civil de la compraventa mercantil. En este sentido, el autor concluye que: “[...] en virtud de la reserva, [el contrato de compraventa internacional] debeprobarsepor escrito en ambos casos, sin relación al valor de la cosa sobre la que versa el contrato"78.

Tampoco estamos de acuerdo con esta interpretación. La reserva no produce como consecuencia inmediata que el contrato deba probarse por escrito, sino que esto dependerá, en definitiva, de la legislación que deba aplicarse en reemplazo de las normas de la Convención excluidas por la reserva. Si esta legislación es la chilena, la única limitación que podemos encontrar relativa a la prueba del contrato es la de los artículos 1708 y $1709 \mathrm{CCCh..}$ Sin embargo, estas normas sólo serán aplicables cuando no sean desplazadas por las disposiciones del Código de Comercio, en tanto ley especial en esta materia; y, aún en estos casos, su efecto será simplemente excluir la prueba testimonial para acreditar el contrato de compraventa internacional sin que ello impida probarlo por lo demás medios probatorios.

contrato de compraventa interno, mientras el contrato de compraventa internacional sujeto a las normas de la Convención (y a la reserva) sería, en cambio, solemne.

${ }^{77}$ Maluenda, Rodrigo, Contratos internacionales en el Derecho chileno (Santiago, ConoSur, 1998), pp. 196-197.

${ }^{78}$ Ibíd., p. 337. 
Atendido estas razones, estimamos que la interpretación de Maluenda debe ser igualmente descartada.

\section{COMENTARIO A Un FALlo NACIONAL \\ QUE INTERPRETÓ Y APLICÓ LA RESERVA DEL ARTÍCULO 96 CV.}

El fallo al cual nos referimos fue pronunciado por la Corte de Apelaciones de San Miguel el 2 de julio del año 2003, siendo confirmado por la Corte Suprema el 10 de agosto de $2005^{79}$. Los hechos son básicamente los siguientes.

Un grupo de sociedades francesas vendieron a una sociedad chilena una serie maquinarias e insumos agrícolas, quedando constancia de esto en diversos documentos, entre ellos, facturas y guías de despacho, sin que existiera, empero, contrato alguno otorgado por escrito entre las partes. Las sociedades francesas luego cedieron sus créditos a una sociedad chilena y esta última decidió demandar a la sociedad deudora ante los tribunales chilenos, para así obtener el pago de los créditos que previamente había adquirido.

Pues bien, ni en primera ni en segunda instancia las partes hicieron referencia alguna a la Convención; por el contrario, se limitaron a litigar única y exclusivamente sobre la base del derecho interno ${ }^{80}$.

Al examinar los hechos, sin embargo, la Corte de Apelaciones de San Miguel notó que la controversia versaba sobre créditos cuya causa eran contratos de compraventa internacional de mercaderías, por lo que decidió aplicar la Convención tras comprobar que las partes originarias tenían sus establecimientos en Estados signatarios diferentes (Francia y Chile) y que no había evidencia de que éstas hubieran acordado excluir la aplicación de la Convención a su contrato, conforme lo dispuesto en su artículo 6.

Sin embargo, al referirse al ámbito de aplicación de la Convención la Corte sostuvo que, "a virtud de la reserva antes indicada, y de lo preceptuado por el artículo 4 recién recordado, la "Convención de Viena" sólo regula, del contrato que ocupa este análisis, lo concerniente a sus efectos, esto es, a los derechos y obligaciones que nacen para las partes, comprador y vendedor, una vez celebrado el convenio" (considerando $\mathrm{N}^{\circ} 4$ ). Agrega la Corte que: "establecido como está que, para los efectos de determinar la formación, existencia, o prueba del contrato no rigen en la especie las normas de la 'Convención de Viena', preciso es concluir que en la situación de nuestro pais, la compraventa internacional de

79 “Sociedad Gildemeister S.A. con Sociedad Agrícola Gildemesiter S.A.”, Corte Suprema, 10 de agosto de 2005, rol N ${ }^{\circ} 2528-2003$.

${ }^{80}$ Respecto a la posibilidad de excluir la aplicación de la Convención a raíz de este hecho, véase: FERrARI, Franco, cit. (n. 13), pp. 130-132. 
mercaderias plantea mayores exigencias para su formación que la compraventa de mercaderías en el ámbito nacional" (considerando $\mathrm{N}^{\circ} 15$ ).

Como se aprecia de estos considerandos, la Corte estimó que el efecto de la reserva era el de excluir por completo la formación del contrato del ámbito de aplicación de la Convención, por lo que, a su juicio, no solo resultaban inaplicables las disposiciones de la Convención que permiten "que la celebración, la modificación o la extinción por mutuo acuerdo del contrato de compraventa, o la oferta, la aceptación o cualquier otra manifestación de intención, se hagan por un procedimiento que no sea por escrito", sino que la parte II de la Convención por completo. Así, a juicio de la Corte, la formación del contrato de compraventa internacional de mercaderías en Chile escaparía a la regulación de la Convención. Esto no es efectivo, y nos remitimos a lo señalado al abordar la interpretación que hace Sandoval sobre la materia.

Ahora bien, y sin perjuicio de lo anterior, a juicio de la Corte: "el hecho de que la compra, como la que se analiza, deba constar por escrito, no conlleva necesariamente el otorgamiento de un acabado pacto, por escrito". Citando a López Blanco, la Corte sostiene que: "basta simplemente, que los términos del referido convenio consten, de alguna manera por escrito: sea, en un solo convenio, suscrito por ambas partes, o también, a través, de intercambio de correspondencia en que consten la oferta y su aceptación" (considerando $\mathrm{N} 15^{\circ}$ ).

De este modo, y tras analizar la prueba rendida, la Corte estimó que era posible dar por acreditado la existencia de un contrato de compraventa entre las partes. Sin embargo, debido a su particular interpretación de la reserva, no aplicó a esta materia ninguna disposición de la Convención. Como el demandado, eso sí, no acreditó haber pagado el precio de las mercaderías que recibió, la Corte acogió la demanda y lo condenó a pagar al actor el importe de las facturas.

Esta interpretación de la reserva nos parece del todo desafortunada. Primero que nada, la Corte debió haber precisado el lugar de celebración del contrato a fin de determinar si el mismo se encontraba o no sujeto a algún requisito de forma o a alguna limitación probatoria. Es importante recordar al respecto, que Francia no ha formulado la reserva del artículo $96 \mathrm{CV}$. por lo que, de acuerdo a lo que hemos señalado, de ser aplicable su legislación regiría plenamente lo dispuesto en el artículo $11 \mathrm{CV}$.

Ahora bien, suponiendo que la residencia del aceptante se encuentra en Chile y que, por tanto, el contrato debió entenderse celebrado en nuestro país, para establecer los efectos prácticos de la reserva la Corte debió haber determinado si al contrato le era aplicable el estatuto civil o el estatuto comercial. En el primer caso, el efecto de la reserva habría sido excluir la prueba testimonial como medio de prueba directo para acreditar la existencia, modificación o terminación del contrato de compraventa. En el segundo, en 
cambio, la reserva no habría producido ningún efecto práctico pues nuestra legislación comercial no ha establecido requisito de forma o prueba alguno en relación a la contrato de compraventa mercantil.

A diferencia de esto, la Corte sostuvo que producto de la reserva el contrato de compraventa internacional debía necesariamente constar por escrito (aunque entiende que este requisito se satisface con lo que pareciera ser un principio de prueba por escrito). Esta interpretación de los efectos de la reserva nos parece errada y nos remitimos a las razones expuestas precedentemente.

En suma, creemos que este fallo, confirmado por la Corte Suprema ${ }^{81}$, sienta un peligroso y negativo precedente. Esperamos, en consecuencia, que en una siguiente ocasión nuestros tribunales corrijan esta interpretación y enmienden el criterio.

\section{CONCLusiones}

Los principios del consensualismo y la libertad de forma consagrados en la "Convención de Viena" de 1980 han gozado de amplio reconocimiento en el comercio internacional. Prueba de ello encontramos en su consagración normativa en diversos proyectos de armonización y unificación del Derecho llevados a cabo por distintos organismos internacionales. Los tribunales también han enfatizado la importancia de estos principios al aplicar la Convención como queda de manifiesto en los diversos fallos examinados.

Dentro del marco de la Convención, la excepción más importante a estos principios lo constituye la reserva del artículo 96 en relación a su artículo 12 CV. De acuerdo al análisis efectuado, creemos que la interpretación que mejor se ajusta a los propósitos e historia legislativa de la Convención es aquella que sostiene que es necesario acudir a las normas de derecho internacional privado del foro para determinar la legislación aplicable a los requisitos de forma del contrato. De este modo, cuando estas normas se remitan a la legislación de un Estado que no ha formulado la reserva, la Convención, en tanto forma parte de la legislación de dicho Estado, regirá el contrato, lo que importa además aplicar el artículo $11 \mathrm{CV}$. y con ello el principio del consensualismo y la libertad de forma. Si, por el contrario, estas normas se remiten a la legislación doméstica de un Estado reservatario, habrá que analizar dicha legislación a fin de determinar si el contrato debe o no cumplir

\footnotetext{
${ }^{81}$ Nótese que el demandado recurrió de casación en el fondo por falsa aplicación de la Convención al caso, argumentando que ella no resultaba en absoluto aplicable a la controversia. No cuestionó, empero, la aplicación particular y concreta de las normas de la Convención hecha por la Corte.
} 
con algún requisito de forma relativo a su escrituración. En caso de existir tales requisitos, deberá estarse a ellos.

Con todo, esto no quiere decir que en una hipótesis como esta debamos excluir totalmente la aplicación de la parte II de la Convención. Por el contrario, aquellas normas de la Convención relativas a la formación del contrato que no pugnen con lo dispuesto en los artículos 12 y $96 \mathrm{CV}$. subsistirán plenamente aplicables.

Ahora bien, si la norma de conflicto se remite a la legislación chilena tendremos que aplicar nuestra legislación doméstica, en reemplazo de las normas de la Convención excluidas por la reserva. Dado que el contrato de compraventa en Chile es consensual, debemos descartar que el contrato de compraventa regulado por la Convención deba cumplir con alguna solemnidad como requisito para su validez.

En cuanto a las posibles limitaciones probatorias aplicables al contrato de compraventa internacional a consecuencia de la reserva, debemos distinguir si el acto que envuelve la compraventa internacional es civil o mercantil, conforme a las reglas establecidas en nuestro derecho doméstico a estos efectos. De este modo, si el acto puede ser calificado como mercantil la reserva no producirá efectos prácticos ya que nuestra legislación comercial no ha establecido limitaciones particulares en lo que respecta a la prueba del contrato de compraventa.

Si el acto es civil, en cambio, el contrato de compraventa internacional quedará sujeto, en lo respecta a su prueba, a los artículos 1708 y 1709 CCCh. y, por tanto, el efecto de la reserva será (únicamente) excluir la admisibilidad de la prueba testimonial como medio de prueba directo para acreditar la existencia, modificación o terminación del contrato de compraventa internacional.

Con todo, dado el ámbito de aplicación de la Convención y, en particular, lo dispuesto en su artículo 1, en cuanto a excluir las compras hechas para uso personal, familiar o doméstico y, por otra parte, los criterios establecidos por nuestra legislación doméstica para calificar la mercantilidad de un determinado acto, creemos que la regla general será que el contrato de compraventa internacional de mercaderías constituya a su vez un acto de comercio y, en consecuencia, en todos estos casos no estará sujeto a solemnidad alguna relativa al modo en que se perfecciona o prueba; pese a la reserva formulada por nuestro país. 


\section{BibliografíA}

Literatura:

Adame goddard, Jorge, Análisis de un dictamen de la Compromex sobre un caso de compraventa Internacional, en Revista de Derecho Privado, Nueva Serie, 1 (2002).

Alessandri, Arturo. De los contratos (Santiago, Editorial Jurídica, 1994).

Ferrari, Franco - Flechtner, Harry - Brand, Ronald A., The Draft UNCITRAL Digest and Beyond: Cases, Analysis and Unresolved Issue in the U.N. Sales Convention (Londres, Sellier European Law Publishers, 2004).

FLeChtNer, Harry, The Several Texts of the CISG in a Decentralized System: Observations on Translations, Reservations and other Challenges to the Uniformity Principle in Article 7(1), en Journal of Law and Commerce, 17 (1998).

HoNNOLD, John, Uniform Law for International Sales under the 1980 United Nations Convention ( $3^{a}$ edición, La Haya, Kluwer Law International, 1999).

Lookofsky, Joseph M., The 1980 United Nations Convention on Contracts for the International Sale of Goods, en J. Herbots, J. - Blanpain, R. (editores), International Encyclopedia of Laws - Contracts (La Haya, Kluwer Law International, Suppl. 29, de Diciembre de 2000).

López Blanco, José Luis, Compraventa Internacional de Mercaderías (Santiago de Chile, Ace Ediciones y Publicaciones S.A., 2001).

Maluenda, Rodrigo, Contratos Internacionales: en el Derecho chileno (Santiago, ConoSur, 1998).

Marín, Pascual, El nuevo derecho civil de la Rusia Soviética: principios de la legislación civil de la U.R.S.S. promulgados el 1 de mayo de 1962 (Madrid, Instituto Editorial Reus, 1963).

Mereminskaya, Elina, Contratos internacionales e "internacionalización" de contratos nacionales, en Anales de la Facultad de Derecho, $5^{a}$ época, 1 (Universidad de Chile, 2005).

Naciones Unidas, Compendio de jurisprudencia relativo a la Convención de las $\mathrm{Na}$ ciones Unidas sobre los Contratos de Compraventa Internacional de Mercaderías [en línea: http://www.uncitral.org/uncitral/es/case_law/digests.html].

Naciones Unidas, Documento A/CONF.97/5 (1979), Comentarios sobre el Proyecto de Convención sobre los Contratos de Compraventa Internacional de Mercaderías, preparados por la Secretaria. Disponible en: http://www.uncitral.org/pdf/spanish/ cisg/a-conf-97-5.pdf.

PAIllás, Enrique. La compraventa internacional de mercaderías (Santiago, Chile, Editorial Jurídica. de Chile, 2006).

Perales Viscasillas, María del Pilar. Contract conclusion under the CISG., en Journal of Law and Commerce, 16 (Spring 1997).

Perales Viscasillas, María del Pilar. El contrato de compraventa internacional de mercancias ("Convención de Viena" de 1980). [en línea: http://www.cisg.law.pace. $\mathrm{edu} / \mathrm{cisg} / \mathrm{biblio} / \mathrm{perales} 1 / \mathrm{html}]$.

RajSKi, Jerzi. Comments on Article 12" "Comments on Article 11, en BianCa, C. - BoNELL, M., Commentary on the International Sales Law (Milano, Giuffrè, 1987).

Ramírez, Mario, Análisis Crítico del Derecho Internacional Privado Chileno (Santiago de Chile, LexisNexis, 2007).

SAndoval, Ricardo, Los contratos mercantiles (Santiago de Chile, Editorial Jurídica de Chile, 2003). 
Schlechtriem, Peter, Uniform Sales Law - The UN-Convention on Contracts for the International Sale of Goods (Vienna, Manz, 1986).

Schroeter, Ulrich, Backbone or Backyard of the Convention? The CISG's Final Provisions, en EL MISmo, Sharing International Commercial Law across National Boundaries (Wildy, Simmonds \& Hill Publishing, 2008).

VIDAL, Álvaro, La protección del comprador: Régimen de la Convención de Viena y su contraste con el Código Civil (Ediciones Universitarias de Valparaíso, Valparaíso, 2006).

WAng, Xiaolin - Andersen, Camila, The Chinese Declaration against Oral Contracts under the CISG., en Vindobona Journal of International Commercial Law \& Arbitration, 8 (2004).

Winship, Peter, The Scope of the Vienna Convention on International Contracts, en GALsTON, N. - SMIT, H. (editores), International Sales: The United Nations Convention on Contracts for the International Sale of Goods (Matthew Bender, 1984).

YANG, Fan, The Application of the CISG in the Current PRC Law and CIETAC Arbitration Practice, en Nordic Journal of Commercial Law, 2 (2006).

Jurisprudencia:

Alto Tribunal Arbitral de la Federación de Rusia, Arbitraje, 25 de marzo de 1997 [disponible en inglés en: http://cisgw3.law.pace.edu/cases/970325r2.html].

Arbitraje Compromex, México, 29 de abril de 1996 [disponible en inglés en: http:// cisgw3.law.pace.edu/cases/960429m1.html\#ct].

Arbitraje Compromex, México, 4 de mayo de 1993 [disponible en: http://turan.uc3m. es/uc3m/dpto/PR/dppr03/cisg/smexil.htm].

China International Economic \& Trade Arbitration Commission (CIETAC), China, 15 de diciembre de 1997 , caso Clout $\mathrm{N}^{\circ} 715$ [disponible en inglés en: http://cisgw3. law.pace.edu/cases $/ 970415 \mathrm{cl} . \mathrm{html}]$.

Corte de Apelaciones de Helsinki, Finlandia, 26 de octubre de 2000 [disponible en inglés en: http://cisgw3.law.pace.edu/cases/001026f5.html].

Cour d'Appel Grenoble [Corte de Apelaciones de Grenoble, Francia], 28 de noviembre de 2002 [disponible en inglés en: http://cisgw3.law.pace.edu/cases/021128f2. html].

“Empresa Nacional de Frigoríficos S.A. con Horacio Carvajal Cuevas", Corte de Apelaciones de Santiago, 29 de octubre de 1980, en Revista de Derecho y Jurisprudencia, 77 (1980), sección $2^{\text {a }}$.

Federal Court of Appeals for the Eleventh Circuit, Estados Unidos, 29 de junio de 1998, caso Clout, $\mathrm{N}^{\circ} 222$ [disponible en inglés en: http://www.cisg.law.pace.edu/ cases/980629u1.html].

Federal Court, South Australian District, de Adelaidede, Australia], 28 de abril de 1995, disponible en inglés en: http://www.cisg.law.pace.edu/cases/950428a2.html\#ta].

Federal District Court [Southern District of Ohio, Estados Unidos], 26 de marzo de 2009 [disponible en inglés en: http://cisgw3.law.pace.edu/cases/090326u1. html].

Federal District Court de Florida, 19 de mayo de 2008 [disponible en inglés en: http:// cisgw3.law.pace.edu/cases/080519u2.html].

Federal District Court de Nueva Jersey, 7 de octubre de 2008 [disponible en inglés en: http://cisgw3.law.pace.edu/cases/081007u1.html]. 
Federal District Court de Pennsylvania [Estados Unidos], 29 de enero de 2010 [disponible en inglés en: http://cisgw3.law.pace.edu/cases/100129u1.html\#iii].

Handelsgericht des Kantons St. Gallen [Tribunal de Comercio], Suiza], 5 de diciembre de 1995, caso Clout, $\mathrm{N}^{\circ} 330$ [disponible en inglés en: http://cisgw3.law.pace.edu/ cases/951205s1.html].

Hooge Raad [Corte Suprema, Holanda], 7 de noviembre de 1997.

ICC Arbitration Case N $^{\circ} 9117$ de marzo de 1998 [disponible en inglés en: http://www. unilex.info/case.cfm?pid=1\&do=case\&id=399\&step=Abstract $]$.

Landgericht Memmingen [Tribunal de primera instancia, Alemania], 1 de diciembre de 1993, [disponible en inglés en: http://www.unilex.info/case.cfm?pid=1\&do=c ase\&id $=113 \&$ step $=$ Abstract $]$.

Landgericht Potsdam [Tribunal de primera instancia de Potsdam, Alemania], 7 de abril de 2009 [disponible en inglés en: http://cisgw3.law.pace.edu/cases/090407g1. html].

Oberlandsgericht Graz [Corte de Apelaciones de Graz], Austria, 7 de marzo de 2002, caso CLOUT No. 537, disponible en inglés en: http://cisgw3.law.pace.edu/ cases/020307a3.html].

Oberlandsgericht Köln [Corte de Apelaciones de Colonia, Alemania], 22 de febrero de 1994, disponible en inglés en: http://cisgw3.law.pace.edu/cases/940222g1.html].

Oberlandsgericht München [Corte de Apelaciones de Munich], Alemania], 8 de marzo de 1995 [disponible en inglés en: http://www.unilex.info/case.cfm?pid=1\&do=c ase\&id $=119 \&$ step $=$ Abstract $]$.

Oberster Gerichtshof [Corte Suprema, Austria], 17 de diciembre de 2003 [disponible en inglés en: http://cisgw3.law.pace.edu/cases/031217a3.html].

Oberster Gerichtshof [Corte Suprema, Austria], 29 de junio de 1999, caso Clout N ${ }^{\circ} 424$ [disponible en inglés en: http://cisgw3.law.pace.edu/cases/990629a3.html].

Oberster Gerichtshof [Corte Suprema, Austria], 6 de febrero de 1996, caso Clout, $\mathrm{N}^{\circ}$ 176 [disponible en inglés en: http://cisgw3.law.pace.edu/cases/960206a3.html].

Rechtbank Breda [Tribunal de primera instancia de Breda, Paises Bajos], 16 de enero de 2009 [disponible en inglés en: http://cisgw3.law.pace.edu/cases/090116n1. html].

Rechtbank Rotterdam [Tribunal de Primera Instancia de Rotterdam, Países Bajos], 12 de julio de 2001 [disponible en inglés en http://cisgw3.law.pace.edu/cases/010712n1. html].

Rechtbank van Koophandel [Tribunal de Primera Instancia, Hasselt, Bélgica], 2 de mayo de 1995, disponible en inglés en: http://www.unilex.info/case.cfm?pid=1\& $\mathrm{do}=$ case $\& \mathrm{id}=263 \&$ step $=$ Abstract $]$.

"Sociedad Gildemeister S.A. con Sociedad Agrícola Gildemesiter S.A.", Corte Suprema, fecha 10 de agosto de 2005, rol N²528-2003.

Tribunal de Arbitraje Comercial Internacional de la Cámara de Comercio e Industria de la Federación Rusa, 16 de febrero de 2004 [disponible en inglés en: http://cisgw3. law.pace.edu/cases/040216r1.html].

Tribunal de Primera Instancia de Dolny Kubin, Eslovaquia], 17 de junio de 2008, disponible en inglés en: http://cisgw3.law.pace.edu/cases/080617k1.html].

Fuentes:

Bases de la legislación civil de la Unión de Repúblicas Socialistas Soviéticas y de las Republicas Federadas. 
Código Civil de Chile.

Código de Comercio de Chile.

Convención sobre el Derecho de los Tratados, Viena, 1969.

Convención sobre la Compraventa Internacional de Mercaderias, Viena. 1980.

Convención sobre el reconocimiento y la ejecución de las sentencias arbitrales extranjeras,

Nueva York, 1958

Principios del Derecho Europeo de los Contratos, 2002.

Principios formulados por el Instituto Internacional para la Unificación del Derecho Privado (UNIDROIT) del año 2004.

Uniform Commercial Code (UCC), Estados Unidos de Norteamérica. 
